\title{
ИНТЕГРИРОВАННАЯ ОЦЕНКА ИНВЕСТИЦИОННО-ДЕВЕЛОПЕРСКИХ ПРОЕКТОВ "
}

\section{(c) 2020 Хейфец Елизавета Евгеньевна}

аспирант департамента корпоративных финансов и корпоративного управления Финансовый университет при Правительстве Российской Федерации, Россия, Москва E-mail: liza.kheifetz@yandex.ru

В статье представлен анализ возможности применения интегрированной оценки в рамках выполнения инвестиционно-девелоперских проектов, а также анализ основных существующих проблем в отечественной практике системного стратегического анализа девелоперских проектов.

Ключевые слова: инвестиционно-девелоперский проект, интегрированная оценка, инвестиционный анализ, инвестиции, проект девелопмента, стратегический анализ

В основе финансового развития любой организации лежит реализация инвестиционных проектов, основанная на методологических подходах, целью которых является образование новых или улучшение действующих активов предприятия, является имманентной составляющей процесса развития большинства инновационных организаций. Реализация инвестиционных проектов способствует созданию в будущем денежных потоков, аккумулированию высокой добавленной стоимости товаров и услуг и в целом достижению целей развития компании [4].

В условиях текущей глобальной нестабильности, взаимных санкций, высокой волатильности, ограниченных возможностях использования средств российского и международного финансового рынка капитала растет актуальность решения, проблемы повышения качества инвестиционного анализа и научно-экономического обоснования проектных инвестиций, применения наиболее надежных и продуктивных форм и инструментов финансирования проектов, включая и проектное финансирование.

С развитием строительной отрасли и отрасли девелопмента недвижимости, а также с принятием особо важных принципов модернизации (ввод эскроу-счетов), повышается важность адекватной оценки инвестиционнодевелоперских проектов

Методология анализа инвестиционно-девелоперского проекта является основой инвестиционной деятельности и инвестиционной политики девелопера.

Инвестиционный анализ девелоперского проекта - это проведение оценки и анализа проекта на всех стадиях жизненного цикла проекта (предынвестиционной, инвестиционной и операционной) в целях достижения запланированных результатов и обеспечения взвешенного принятия решения о его реализации [8]. Инвестиционный анализ - важнейший аспект реализации инвестиционного проекта, выполняемый как руководством проекта, так и иными заинтересованными участниками проекта, особенно инвесторами.

Классическое понимание интегрированной оценки инвестиционно-девелоперских проектов, в частности в отечественной практике, обычно сводится к анализу финансовой реализуемости и эффективности проекта на предынвестиционной стадии первичного планирования для обоснования целесообразности вхождения в проект, построения структуры финансирования и его финансовой модели.

Анализ зарубежной и отечественной практики в методологии оценки инвестиционных проектов дает возможность определить семь базовых принципов современного интегрированного инвестиционного анализа проектов, некоторые из которых не применяются в российской практике [7]. Тем не менее, не все являются актуальными в случае рассмотрения именно инвестиционно-девелоперских проектов. Рассмотрим их далее.

Первый принцип - непрерывность применения инвестиционного анализа. В интегрированной оценке инвестиционно-девелоперского проекта принцип соблюдается на всех стадиях жизненного цикла проекта (некоторыми участниками - вплоть до выхода из инвестиционно-

* Статья также соответствует специальности 08.00.10 
девелоперского проекта) в целях контроля и своевременного планирования результатов проекта и затрат, а также соблюдения интересов участников девелопмента. Непрерывность инвестиционного анализа в процессе наблюдения за реализацией девелоперского проекта должна обеспечить полное соответствие фактических результатов проекта с плановыми [5].

Второй принцип - это системность анализа девелоперского проекта, т.е. учет системы отношений между исполнителями проекта и их финансовым окружением, важнейших факторов, которые влияют на издержки и результаты любого участника инвестирования, а также внешних, внутренних и синергетических эффектов. Для данного учета в план инвестиционногодевелоперского проекта должна быть включена расшифровка возможного механизма взаимодействия между участниками проекта (организационный механизм реализации проекта). Системный подход подразумевает учет целей, рисков и интересов всех участников девелоперского проекта, существенных последствий исполнения, как непосредственно финансовых, так и внеэкономических (экологические, социальные, суверенные и др.) с возможной экспертной или количественной оценкой [5].

Степень разработанности и объем работы аналитика при инвестиционном анализе зависит от капиталоемкости проекта, масштаба, социально-экономических последствий исполнения, региона, степени влияния на смежные экономические отрасли, участия государства.

Третий принцип интегрированного анализа состоит в исполнении дифференцированного подхода к анализу инвестиционнодевелоперского проекта. В частности, в западных банках дифференцированный подход к объему, глубине, критериям жизнеспособности инвестиционного проекта используется для прибыльных и экономически эффективных проектов и неспособных давать прибыль [7].

Четвертый принцип анализа касается исследования стоимостных параметров и индикаторов коммерческой и инвестиционной эффективности девелоперского проекта и заключается в анализе показателей экономической эффективности в системе рыночной стоимости. Данный принцип анализа проекта неразрывно связан с первым и дает возможность оценить вклад инвестиционно-девелоперского проекта в развитие, как на макроэкономическом, так и на корпоративном уровне [5].

Пятым принципом анализа проекта является повышение требования к инструментам технического и экономического мониторинга, аудита и контроля параметров инвестиционнодевелоперского проекта и итогов его реализации. Необходимым условием исполнения данного принципа является использование современных BIM-технологий и иных, относящихся к категории PropTech (англ. Property Technology - технологии в недвижимости). Однако согласно недавнему исследованию компании РwC, практически половина (45\%) респондентов - игроков рынка недвижимости, не планирует в ближайшее время начинаться использование BIM-технологий. Среди причин - слишком высокая стоимость внедрения и долгий срок окупаемости. Тем не менее, в то же самое время для федеральных проектов с участием государства использование автоматизированных систем управления является обязательным условием получения государственных субсидий и дотаций [5].

Шестым принципом анализа проектов является комплексный характер с применением множества критериев, предусматривающий использование различных научных видов анализа инвестиционного проекта [5]. Любой вид анализа обладает определенными целями и критериями оценки и дает возможность исследовать и выявить динамику влияния и изменения в проекте различных видов рисков инвестора.

Исполнение интегрированного подхода к анализу девелоперских проектов соответствует международной практике и включает ряд разновидностей анализа:

- стратегический анализ инвестиционного проекта на соответствие его задач, целей и ожидаемых результатов стратегии девелопера (региона, банка, страны, отрасли);

- экспресс-анализ (актуально для основных технико-экономических показателей, основных выводов);

- институциональный, правовой анализ;

- коммерческий анализ инвестиционного проекта;

- анализ рисков проекта, включая стресстестирование и анализ чувствительности, моделирование воздействия рисков на финансовые потоки проекта с учетом изменения воздействующих факторов и условий;

- экологический анализ проекта;

- оценка эффективности и финансовой реа- 
лизуемости, финансово-экономический анализ проекта [1].

Проектный экспресс-анализ на этапе первичной оценки может проводиться и инициатором проекта (то есть девелопером) с целью представления потенциальным инвесторам, кредиторами и инвесторами. Девелопер определяет возможности выполнения проекта и эффективности вложений в него перед разработкой документации проекта.

Стратегический анализ инвестиционного проекта, исполняемый девелопером и отражаемый в плане, заключается в аналитике соответствия задач проекта и стратегии развития девелоперской компании (региона, отрасли, страны). Стратегический анализ инвестиционнодевелоперского проекта, выполняемый девелопером и отражаемый в заключении о необходимости участия инвесторов в финансировании проекта, состоит в определении соответствия задач проекта стратегии девелопера и инвестиционной политики и стратегии банка.

Технический анализ инвестиционного проекта на начальной стадии производится с целью определения основных технико-экономических параметров. На стадии исполнения проекта наблюдения технологических и технических решений является обязательным условием управления проектом со стороны государства и для девелопера в качестве подотчетного лица.

Коммерческий анализ девелоперского проекта (или маркетинговый) необходим для определения коммерческих рисков инвестиционнодевелоперского проекта, связанного с будущей стоимостью квадратного метра жилой площади (а также коммерческих и бытовых), прогнозом объемов и темпов продаж. Данный анализ выполняется в виде изучения конкурентного окружения, а также включает в себя проработку таких аспектов как объем предложения, объем будущего спроса и предложения.

Экологический и социальный анализ проекта в отечественной практике до сих пор не получил нужного распространения, однако в последнее время имеет все большее значение. Существующие сегодня экологические проблемы ухудшаются с увеличением плотности и этажности жилой застройки. Среди причин в том числе сокращение площади зеленых насаждений, повышенный миграционный поток, отказ от гуманной застройки в пользу коммерчески выгодной.
Девелоперы, которые сегодня включают экологический и социальный анализ в разработку стратегического анализа инвестиционнодевелоперского проекта, таким образом повышают непрямыми экономическими методами стоимость своих проектов, а соответственно, и стоимость их последующей реализации на операционной стадии.

Базовые проблемы, которые беспокоят сегодня российские инвестиционные и оценочные сообщества, связаны с разрывом между современной отечественной научно-методической школой оценки инвестиционно-девелоперских проектов от принятой в международной практике.

Текущая зарубежная методология оценки и анализа эффективности инвестиционных проектов базируется на методологии «затратывыгоды» с использованием известных методов дисконтирования денежных потоков и расчетах показателей IRR, NPV, PBP и пр. Согласно CBA чистый общественный эффект инвестиционного проекта определяется как разность общественных затрат и дисконтированных общественных выгод [11].

В зависимости от задачи оценки различают оценку воздействия, предварительную оценку, сводную оценку. В зависимости от позиции оценщики различают внутреннюю самооценку, независимую оценку, совместную, оценку субъектами проекта.

В экономическом анализе инвестиционнодевелоперского проекта также учитываются эффекты внешней среды проекта, приводящие к общественным издержкам и выгодам, не учитываемым при анализе проекта, поскольку они не дают реальных финансовых затрат или дохода (к примеру, воздействие на экологическую среду или влияние на смежные отрасли).

В соответствии с документацией Комитета содействия развитию ОЭСР (Организации экономического сотрудничества и развития), а также с учетом практической реализации международными банками оценки результатов реализации проектов и программ развития проводится с помощью дополнительных и основных критериев [9].

Базовыми являются критерии эффективности, релевантности, устойчивости, результативности и воздействия.

Дополнительным критериями оценивания результатов проектов являются: 
- другие показатели степени вклада на уровень доходов, окружающую среду и пр.;

- показатель институционального развития, который определяется как степень влияния проекта на экономику региона или страны, степень использования финансовых, человеческих и природных ресурсов;

- эффективность заемщика - объем ответственности заемщика на этапах исполнения проекта, особенно на стадии выбора проекта, и обеспечение поддержки всех участников инвестиционно-девелоперского проекта [10].

Эффективность оценки девелоперского проекта (с точки зрения учета всех рисков и целей инвесторов) зависит от собственно методологии анализа и инструментов, организации данной деятельности в банках, компаниях, ведомствах и министерствах.

Современная методология РФ инвестиционного анализа и оценки эффективности проектов базируется на методологии финансового анализа ЮНИДО и Всемирного банка, ее изложение представлено в изысканиях Лившица В.Н. и других авторов. Базовыми действующими методическими документами, по инвестиционной оценке, эффективности является вторая редакция 1999 г. «Рекомендаций по оценке эффективности инвестиционных проектов» и «Методика расчета показателей и применения критериев эффективности региональных инвестиционных проектов, претендующих на получение государственной поддержки за счет бюджетных ассигнований» разработанный Инвестиционным фондом РФ [13].

Однако в отечественной практике отсутствует нормативно-правовое обеспечение инвестиционного анализа непосредственно девелоперских проектов по причине недостаточности развития данного вопроса.

Состояние текущей методологии оценки инвестиционно-девелоперских проектов в РФ вызывает озабоченность профессионалов в данной области и обуславливает необходимость дальнейшего изучения с учетом особенностей экономики РФ.

Перечень базовых показателей, используемых для расчетов общественной и коммерческой экономической эффективности инвестиционных проектов на начальной стадии в российской и зарубежной практике практически идентичен:

- индексы доходности затрат и инвестиций;

- внутренняя норма доходности;

- чистая дисконтированная стоимость проекта [12].

Критерий эффективности инвестиционного проекта (максимум NPV проекта) должен быть генеральным критерием обоснования получения государственной поддержки для исполнения проекта.

Сегодняшнее состояние методического обеспечения инвестиционного анализа и аналитики эффективности девелоперского проекта требует гармонизации и актуализации с текущей международной методологией включая специфический характер российской экономики и особенности развития рынка девелопмента в стране. Анализ проектов в течение всего жизненного цикла должен давать информацию для достижения соответствия запланированных и фактических результатов и параметров финансирования.

Большую поддержку развитию методологии оценки инвестиционно-девелоперских проектов, управления и оценки инвестиционных рисков могло бы оказать создание виртуальных баз данных об опыте и результатах реализации инвестиционно-девелоперских проектов в РФ, эффектах, их стоимости, рисках и их вкладе.

\section{Библиографический список}

1. Зайцев Н.Л. Экономика, организация и управление предприятием учеб. пособие / Н.Л. Зайцев.- М.: ИНФРА, 2012.- 455 с.

2. Бланк И. А. Инвестиционный менеджмент: учебный курс /И. А. Бланк.- К.: Эльга - Н, Ника Центр, 2010.$448 \mathrm{c.}$

3. Багиев Г.Л. Организация предпринимательской деятельности: учеб. пособие / Г. Л. Багиев, А.Н. Асаул; под ред. Г. Л.Багиева.- СПб: Изд-во СПГУЭФ, 2011.-231 с.

4. Лапыгин Ю.Н. Инвестиционная политика: учеб. пособие / Ю. Н. Лапыгин, А.А. Балакирев, Е. В. Бобкова и др.; под ред.Ю. Н. Лапыгина.-М.: КНОРУС, 2015.- 320 с.

5. Никонова И.А. Проектное финансирование в России. Проблемы и направления развития / Никонова И.А., Смирнов А.Л.- М.: Издательство «Консалтбанкир», 2016-216 с. 
6. Бланк И. А. Основы финансового менеджмента. Т. 1, 2. / И.А. Бланк. - К.: Эльга - Н., Ника - Центр, 2011.1104 c.

7. Гитман Л. Дж. Основы инвестирования: учебник для вузов: Пер. с англ. / Л. Дж. Гитман, М.Д. Джонк.- М.: Дело, 2010.- 1008 с.

8. Зимин А. И. Инвестиции: вопросы и ответы / А.И. Зимин.- М.: ИД «Юриспруденция», 2014.-256 с.

9. Райзберг Б.А. Современный экономический словарь / Б.А.Райзберг, Л.Ш. Лозовский, Е. Б. Стародубцева; под общ. ред. Б.А. Райзберга. - 6-е изд., перераб. и доп.- Москва: Инфра - М, 2010. - 512 с.

10. Максимова, В.Ф. Инвестиционный менеджмент: учеб.- практ. пособие / В. Ф. Максимова.- М: Изд. центр ЕАОИ.-М., 2015.- 214 c.

11. Топсахалова Ф. М - Г. Инвестиции / Ф. М - Г. Топсахалова - М.: Изд-во «Академия Естествознания», 2010.$173 \mathrm{c.}$

12. Чиненов М.В. Инвестиции: учеб. пособие / М.В.Чиненов и [др.]; под ред. М.В.Чиненова.- М.: КНОРУС, 2007.- 248 c.

13. Малиновская О.В. Инвестиции: учеб. пособие / О.В.Малиновская, И.П.Скобелева, Н.В.Легостаев: под ред.д.э. н., проф. И.П. Скобелевой.-СПб.: СПгУВК, 2013.-186 с.

14. Ткаченко И. Ю. Инвестиции: учеб. пособие для вузов / И. Ю. Ткаченко, Н. И. Малых. - М.: Изд. центр «Академия», 2012.- 240 с.

15. Чернов В.А. Инвестиционная стратегия: учеб. пособие для вузов / В.А.Чернов.- М.: ЮНИТИ - ДАНА, 2013. -158 c.

16. Бланк И.А. Управление денежными потоками / И.А.Бланк.-2- е изд., перераб. и доп.- К.: Ника-Центр, 2012. - 752 с. 94 